\author{
(1) Deniz Kizılaslan, \\ (1) Seval Ürkmez, \\ (1) Yalım Dikmen, \\ (D) Oktay Demirkıran, \\ (D) Tuğhan Utku
}

\section{Comparison of the Effects of Standard and Diabetes- Specific Dietary Products on Tight Blood Glucose Control in Critically III Patients}

\author{
Kritik Hastalarda Standart ve Diyabete Özgü Beslenme \\ Ürünlerinin, Sıkı Kan Şekeri Kontrolü Üzerine Etkilerinin \\ Karşılaştırılması
}

Geliş Tarihi/Received : 10.05.2019

Kabul Tarihi/Accepted : 26.08.2019

๑) Telif Hakkı 2019 Türk Yoğun Bakım Derneği Türk Yoğun Bakım Dergisi, Galenos Yayınevi tarafından yayınlanmıştır.

Deniz Kızılaslan

Istanbul Medipol Üniversitesi Tıp Fakültesi, Anesteziyoloji ve Reanimasyon Anabilim Dall, Istanbul, Türkiye

Seval Ürkmez, Yalım Dikmen, Oktay Demirkıran Istanbul Üniversitesi Cerrahpaşa, Cerrahpaşa Tıp Fakültesi, Anesteziyoloji ve Reanimasyon Anabilim Dalı, Yoğun Bakım Bilim Dalı, Istanbul, Türkiye

Tuğhan Utku

Yeditepe Tıp Fakültesi, Anesteziyoloji ve

Reanimasyon Anabilim Dalı, Istanbul, Türkiye

Dr. Deniz Kızlaslan (困),

Istanbul Medipol Üniversitesi Tıp Fakültesi, Anesteziyoloji ve Reanimasyon Anabilim Dalı, Istanbul, Türkiye

E-posta : dnzkzlsIn@gmail.com

Tel. : : +905308271488

ORCID ID : orcid.org/0000-0001-6587-8103

Sunulduğu Kongre: Yazı sözlü sunu olarak 11. KEPAN Kongresi'nde sunulmuştur.
ÖZ Amaç: Beslenme desteği, yoğun bakım tedavisinin bir parçasıdır. Çalışmamızda hiperglisemik kritik yoğun bakım hastalarında diabete özgü enteral ürün ile standart enteral ürünün sıkı kan şekeri kontrolü ve insülin intiyacı üzerine etkilerini araştırdık.

Gereç ve Yöntem: Çalışma prospektif, randomize, 'cross over' karşılaştırmalı çalışma olarak planlandı. Enteral ürün alımını tolere eden hastalarda günlük alması gereken kalori gereksinimleri 25 kcal x vücut ağırlığı olarak hesaplandı. Kalori gereksinimleri 21 saate bölünerek saatlik kalori intiyaçları ve beslenme ürünü volümü hesaplandı.80 hasta 2 gruba ayrılarak 1.gruba ilk 24 saatte Isosource Standart, 2.gruba ise Novasource Diabet verildi. Ikinci 24 saatte 1.gruba Novasource Diabet, 2. gruba ise Isosource Standart verildi. Kan şekeri düzeyini $80-150 \mathrm{mg} / \mathrm{dL}$ düzeyinde tutacak şekilde intravenöz yoldan insülin infüzyonu verildi. 4 saatte bir kan şekeri düzeyi arter kan gazı alınarak ölçüldü.

Bulgular: Çalışmamızda en yüksek, en düşük, ortalama ve medyan kan glukoz değerleri ile toplam insülin, ortalama insülin düzeyleri ve insülin doz değişiklik sayısı kaydedildi. En yüksek, en düşük ve ortalama kan glukoz değerleri açısından her iki ürün arasında anlamlı bir fark bulunmadı. Her iki grupta medyan kan glukoz düzeyleri karşılaştırılı̆ğında sayısal olarak anlamlı görülse de istatistiksel olarak anlamlı bir fark bulunamadı.

Sonuç: Diyabetik olmayan kritik hastalarda diyabete özgü ürünün sıkı kan şekeri kontrolünde çok büyük bir katkısı olmadığı sonucuna varıldı.

Anahtar Kelimeler: Şeker, hiperglisemi, insülin, beslenme

ABSTRACT Objective: Nutritional support is a part of intensive care unit therapy. In our study, we investigated the effects of diabetes-specific enteral formula and standard enteral formula on tight blood glucose control and insulin requirement in hyperglycemic intensive care unit patients.

Materials and Methods: The study was planned as a prospective, randomized, crossover comparative study. The daily caloric requirements for patients who tolerated enteral product intake were calculated as $25 \mathrm{kcal}$ x body weight. Calorie requirements were divided into 21 hours and hourly calorie needs and nutrient volume were calculated. Eighty patients were divided into two groups. First group received ISOSOURCE $®$ Standard and second group received Novasource $₫$ Diabetes in the first 24 hours. In the second 24 hours, Group 1 received Novasource $®$ Diabetes, while Group 2 received Isosource $\AA^{\circledR}$ Standard. An intravenous insulin infusion was given to maintain the blood glucose level at 80-150 mg / dL. Blood glucose level was measured every 4 hours by taking arterial blood gas. Maximum, minimum, mean and median blood glucose levels, total insulin, mean insulin levels and the number of insulin dose changes were recorded.

Results: No statistically significant difference was observed between two groups in terms of maximum, minimum and mean blood glucose levels. When compared, median blood glucose levels were numerically significant, but were not statistically significant in both groups.

Conclusion: It was concluded that diabetes-specific enteral formula did not contribute significantly to tight blood glucose control in non-diabetic critical patients.

Keywords: Glucose, hyperglycemia, insulin, nutrition 


\section{Giriş}

Hastalık veya travma sonucu yaşam fonksiyonları ileri derecede bozulmuş olan veya her an bozulma riski taşıyan hastalar kritik hasta olarak tanımlanır. Bu tip kritik yoğun bakım hastalarında beslenme desteğinin, hastaların prognozu açısından önemli faktörlerden biri olduğu bilinmektedir ${ }^{11}$.

Erken enteral nütrisyonel destek, parenteral nütrisyona göre; intestinal mukozanın yapısında daha az atrofiye neden olması, infeksiyon oranının daha düşük olması, bakteriyal translokasyonla sepsis değerlerinde azalmaya neden olması ve ucuzluğu gibi nedenlerle daha avantajıdır. Standart bir enteral nütrisyon ürünü kullanımı genel bir kabul görmekle beraber, hastalık spesifik nütrisyon son zamanlarda yapılan çalışmalarla birlikte daha çok tercih sebebi olmuştur(2) .

Sıkı kan glukozu kontrolü son yıllar içerisinde yoğun bakımla ilgili en çok ses getiren ve tartışılan konu olmuştur. Cerrahi yoğun bakımlarda sıkı kan glukozu kontrolü daha iyi klinik sonuçlar ile ilişkili bulunmuştur ${ }^{(3)}$. Diyabet öyküsü bulunmayan, stres metabolik yanıt olarak hiperglisemi gelişen kritik yoğun bakım hastalarında hastalık spesifik enteral beslenme ürününün, standart enteral beslenme ürününe göre daha iyi kan glukozu kontrolü sağlayacağı ve insülin intiyacını azaltacağı öngörülmektedir. Çalışmanın amacı, hiperglisemik kritik yoğun bakım hastalarında diabete özgü enteral ürün ile standart enteral ürünün kan glukozu kontrolü ve insülin ihtiyacı üzerine etkilerini karşılaştırmaktır.

\section{Gereç ve Yöntem}

Prospektif, randomize, 'cross over', karşılaştırmalı bir çalışma olarak planlanan bu çalışma etik kurul onayı alındıktan sonra üçüncü basamak bir üniversite hastanesinin yoğun bakım ünitesinde yapıldı. Yoğun bakım ünitesinde en az 3 gün kalması planlanan ve enteral beslenmeyi tolere edebilecek, ancak ağızdan beslenemeyen, kan glukoz düzeyi 150 mg/dL üzerinde olan 18 yaş ve üzerindeki erişkin hastalar değerlendirildi. Obezite (vücut kitle indeksi $>30 \mathrm{~kg} / \mathrm{m}^{2}$ ), renal replasman tedavisi (RRT) uygulanan hastalar, tip 1 ve tip 2 diyabet öyküsü bulunan ve dolaşım şokundaki hastalar çalışmaya dahil edilmedi. Toplam 80 hasta, onamlarının alınmasını takiben bilgisayar tarafından oluşturulan blok rastlantısal sayı tablosu ile randomize edildi ve iki gruba ayrıldı. Hastalar 3 gün boyunca takip edildi.

Yoğun bakım ünitemizde ağızdan beslenemeyen ve gastrointestinal sistemin kullanılmasında kontrendikasyon olmayan tüm kritik hastalara erken dönemde (24-48 saat) nazogastrik tüpten devamlı infüzyon (Compat Enteral Delivery System) şeklinde enteral beslenme ürünü başlanmakta ve 'enteral beslenme protokollerine' uyularak sürdürülmektedir. Çalışmamızda 24 saatte $75 \mathrm{ml} / \mathrm{saat}$ enteral ürün alımını tolere eden hastalarda günlük alması gereken kalori gereksinimleri 25 kcal x vücut ağırlığı $(\mathrm{kg})$ olarak hesaplandı. Ünitemizde uygulanan enteral beslenme protokolüne göre, beslenme ürünü 7 saat besleme 1 saat ara şeklinde verildiği için günlük enerji gereksinimleri hastalara 21 saatte verilmektedir. Bu nedenle hastaların günlük kalori gereksinimleri 21 saate bölünerek saatlik kalori intiyaçları ve beslenme ürünü volümü hesaplandı. Hastalar 2 gruba ayrılarak 1. gruba ilk 24 saatte Isosource Standart (Nestle HealthCare Nutrition $\mathrm{GmbH}$, Osthofen-Almanya) beslenme ürünü, 2. gruba ise Novasource Diabet (Nestle HealthCare Nutrition $\mathrm{GmbH}$, Osthofen-Almanya) beslenme ürünü verildi. Ikinci 24 saatte 1. gruba Novasource Diabet beslenme ürünü, 2. gruba ise Isosource Standart beslenme ürünü verildi. 7 saat beslenme sonrası verilen 1 saatlik aralarda aspirasyon yöntemiyle rezüdüel volüm ölçüldü. Rezüdüel volüm 150 $\mathrm{mL}$ 'nin üzerinde olan hastalara $10 \mathrm{mg}$ metoklopromid $3 \times 1$ dozunda intravenöz (IV) başlandı. Metoklopromid tedavisine rağmen rezüdüel volümü fazla olan hastalar çalışma dışı bırakıldı. Çalışma süresince hastalara intravenöz yoldan başka dekstrozlu sıvı verilmedi.

Yoğun bakım ünitemizde enteral beslenme uygulanan ve kan glukoz düzeyi 150 mg/dL'nin üzerinde olan tüm hastalarda rutin olarak devamlı intravenöz insülin (Novo Nordisk A/S, DK2880 Bagsvaerd, Danimarka) infüzyonu uygulanmakta ve kan glukoz düzeyleri 4 saatte bir ölçülmektedir. Çalışmamızda da enteral beslenme uygulaması süresince kan glukoz düzeyini 80-150 mg/dL düzeyinde tutacak şekilde intravenöz yoldan devamlı insülin infüzyonu verildi ve 4 saatte bir kan glukoz düzeyi arter kan gazı (ABL 700 SERIES RADIOMETER/ COPENHAGEN) alınarak ölçüldü. Yatış süresince kan glukozu düzeylerine eğer insülin infüzyon dozu değiştirilmemişse 4 saatte bir bakıldı; eğer kan glukozu düzeyinde artış veya düşüş belirlenmişse yeni insülin infüzyon dozu ayarlandıktan bir saat sonra kan glukozu düzeyine yeniden bakıldı. Kristalize insülin $50 \mathrm{IU} / 50 \mathrm{~mL}$ izotonik sıvı ile sulandırılarak $1 \mathrm{IU} / \mathrm{mL}$ konsantrasyonda hazırlanarak devamlı intravenöz infüzyon şeklinde infüzyon pompası (B/BRAUN perfusor Space, made in Germany) ile verildi. Kristalize insülin doz ayarı yoğun bakım ünitemizde uygulanan protokole göre yapıldı. Kan glukozu protokolü Tablo 1'de gösterilmiştir. Hastaların en 
düşük kan glukoz düzeyleri (mg/dL), en yüksek kan glukoz düzeyleri (mg/dL), ortalama kan glukoz düzeyleri $(\mathrm{mg} / \mathrm{dL})$, medyan kan glukoz düzeyleri $(\mathrm{mg} / \mathrm{dL}$ ) ile toplam ve ortalama insulin miktarları (IU) ayrıca insulin doz değişikliklerinin sıklığı karşılaştııılmıştır.

Çalışma verileri değerlendirilirken normal dağılım gösteren parametrelerin gruplar arası karşılaştırmalarında parametrik veriler için 'eşlendirilmemiş t testi', non parametrik veriler için ise Mann Whitney U testi kullanıldı. Değerler ortalama \pm standart sapma olarak ifade edildi. Sonuçlar \% 95'lik güven aralığında, anlamlıık $p<0.05$ düzeyinde değerlendirildi.

\section{Bulgular}

Olguların yaş ortalaması $61.12 \pm 17.96 \mathrm{yll} ; \mathrm{kg}$ ortalaması $72 \pm 9.52 \mathrm{~kg}$; total kalori gereksinimleri ortalaması $1800 \pm$ $238.18 \mathrm{kcal}$ olarak hesaplandı. Olguların APACHE II ortalaması $22.62 \pm 4.24$ olarak bulundu (Tablo 2 ).

Hastaların en düşük kan glukoz düzeyleri; Grup 1'de $96.27 \pm 28.27 \mathrm{mg} / \mathrm{dL}$, Grup 2'de $92.8 \pm 28.24 \mathrm{mg} / \mathrm{dL}$ olarak bulunmuştur. Iki grup en düşük kan glukoz düzeyleri

\begin{tabular}{|c|c|c|}
\hline & $\begin{array}{l}\text { Glukoz düzeyi } \\
\text { (mg/dL) }\end{array}$ & $\begin{array}{l}\text { İnsülin dozu (IU/ } \\
\text { saat) }\end{array}$ \\
\hline \multirow[t]{3}{*}{$\begin{array}{l}\text { YBÜ girişinde ve takip } \\
\text { sırasında }\end{array}$} & $>220$ & $2-4$ \\
\hline & $220-150$ & $1-2$ \\
\hline & $<150$ & $\begin{array}{l}\text { Başlama, her } 4 \\
\text { saatte bir kan } \\
\text { glukoz düzeyi } \\
\text { ölçümü }\end{array}$ \\
\hline \multirow{5}{*}{$\begin{array}{l}\text { Kan glukoz düzeyi } \\
\text { yatış süresince } 4 \\
\text { saatte bir izlenir }\end{array}$} & $80-150$ & $0.1-0.5$ \\
\hline & Hızla düşüyor & $\begin{array}{l}\text { Dozu yarıya in ve } \\
\text { 30dk'da bir kan } \\
\text { glukozuna bak }\end{array}$ \\
\hline & $60-80$ & $\begin{array}{l}\text { İnfüzyonu kes, } \\
1 \text { saatte bir kan } \\
\text { glukozuna bak }\end{array}$ \\
\hline & $40-60$ & $\begin{array}{l}\text { İnfüzyonu kes, } 10 \mathrm{gr} \\
\text { IV glukoz ver ve } \\
30 \mathrm{dk} \text { da bir kan } \\
\text { glukozuna bak }\end{array}$ \\
\hline & $<40$ & $\begin{array}{l}\text { İnfüzyonu kes, } 10 \mathrm{gr} \\
\text { IV glukoz ver ve } \\
30 \text { dk'da bir kan } \\
\text { glukozuna bak }\end{array}$ \\
\hline
\end{tabular}

açısından istatistiksel olarak karşılaştııılığında anlamlı fark bulunmamıştır ( $p>0.05$, grafik 1 ).

Hastaların en yüksek kan glukoz düzeyleri; Grup 1'de $176.6 \pm 45.54 \mathrm{mg} / \mathrm{dL}$, Grup 2'de $169.45 \pm 43.26 \mathrm{mg} / \mathrm{dL}$ olarak bulunmuştur. Iki grup en yüksek kan glukoz düzeyleri açısından istatistiksel olarak karşılaştııılığında anlamlı fark saptanmamıştır ( $p>0.05$, grafik 2).

Hastaların ortalama kan glukoz düzeyleri; Grup 1'de $134.6 \pm 21.81 \mathrm{mg} / \mathrm{dL}$, Grup 2'de $130.2 \pm 23.86$ mg/dL olarak bulunmuştur. Istatistiksel olarak karşılaştırıldığında gruplar arasında ortalama kan glukoz düzeyleri arasında anlamlı fark bulunmamıştır ( $p>0.05)$.

\begin{tabular}{|l|l|}
\hline \multicolumn{2}{|l|}{ Tablo 2. Hastaların demografik verileri } \\
\hline Yaş (yıl \pm SD) & $61.12 \pm 17.96$ \\
\hline Cinsiyet & $\begin{array}{l}\text { Kadın: } 24(\% 30) \\
\text { Erkek: } 56(\% 70)\end{array}$ \\
\hline Vücut ağırlığı ortalaması $(\mathrm{kg})$ & $72 \pm 9.52$ \\
\hline Total kalori gereksinimi (kcal) & $1800 \pm 238.18$ \\
\hline APACHE II & $22.62 \pm 4.24$ \\
\hline
\end{tabular}

SD: standart sapma; APACHE: Acute Physiology and Chronic Health Evaluation; kcal: kilokalori; kg: kilogram

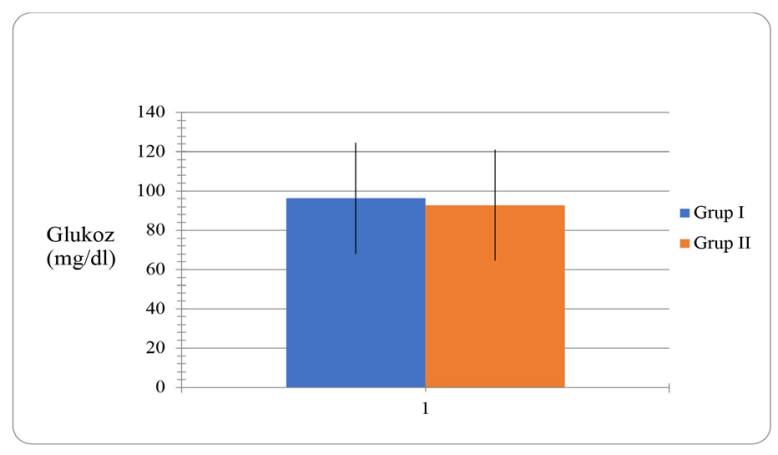

Grafik 1. Grupların ortalama en düşük glukoz değerleri (mg/dl)

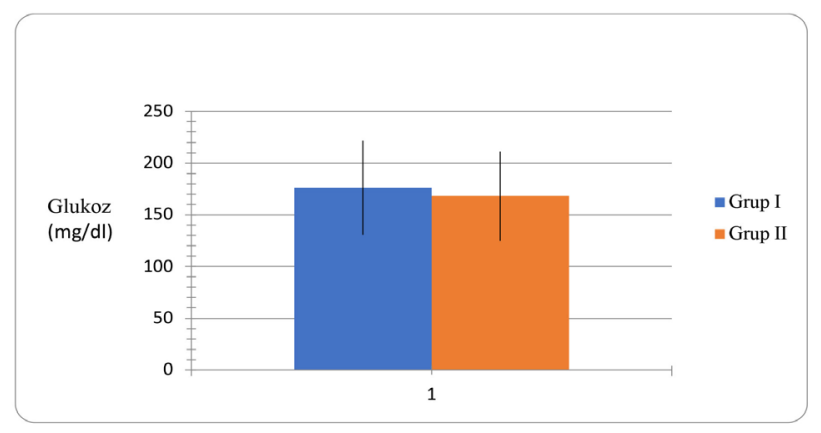

Grafik 2. Grupların ortalama en yüksek glukoz değerleri (mg/dl) 


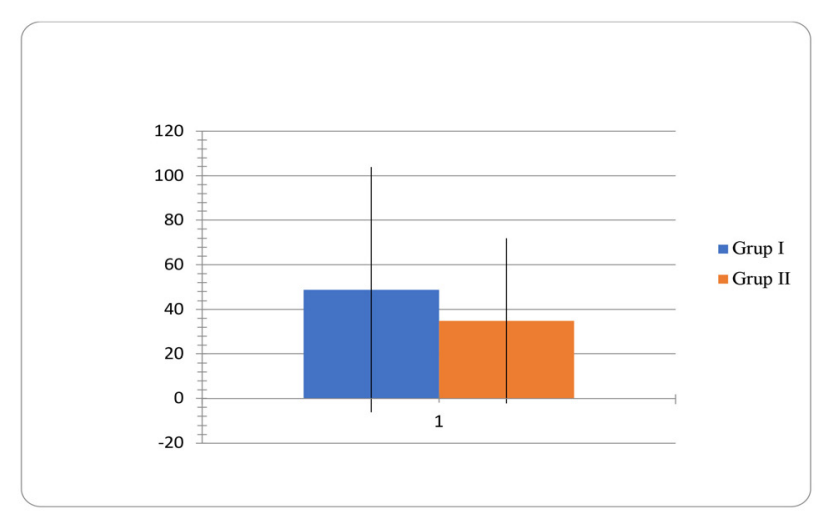

Grafik 3. Grupların ortalama insülin dozları (IU)

Hastalara verilen toplam insülin miktarları (ünite); Grup 1'de $48.75 \pm 55.06$, Grup 2'de $34.97 \pm 37.14$ olarak bulunmuştur. Iki grup toplam insülin miktarları açısından istatistiksel olarak karşılaştııılığında anlamlı fark bulunmamıştır ( $p>0.05)$. Hastalara verilen ortalama insülin miktarları; Grup 1'de $2.06 \pm 2.31$ ünite/saat, Grup 2'de 1.41 \pm 1.51 ünite/saat olarak bulunmuştur. Iki grup ortalama insülin miktarları açısından istatistiksel olarak karşılaştırıldığında anlamlı fark saptanmamıştır ( $p>0.05$, grafik 3 ).

Çalışma bulgularının değerlendirilmesi sırasında toplam ve ortalama insülin miktarlarında istatiksel olarak fark saptanmamakla birlikte insülin doz değişikliklerinin sıklığı karşılaştııılığında standart grupta ortalama doz değişim sayısı $2.8 \pm 2.95$, diyabete özgü ürün verilen grupta ise $1.45 \pm 1.95$ olarak bulunmuştur, bu fark istatistiksel olarak anlamlıdır $(p<0.05)$.

\section{Tartışma}

Biz çalışmamızda diyabetik olmayan kritik yoğun bakım hastalarında, diyabetik bir ürünün sıkı kan şekeri kontrolü üstüne etkisini karşılaştırdık. Bizim çalışmamızda kan glukoz düzeyleri arasında istatistiksel olarak anlamlı fark bulunmamıştır. Çalışmamızda diyabetik ürün kullanılan grupta insülin doz değişiklik sayısının daha az olması istatistiksel olarak anlamlı bulunmuştur. Toplam insülin miktarı değişmese de diyabetik ürün kan glukoz düzeyinin daha uzun süre stabil seyretmesini sağlamaktadır. Bu etki yoğun bakım ünitesinde çalışan hemşire ve doktorun iş gücünü azaltabilir. Yapılan çalışmaların çoğu diyabetik hastalar üzerinde yapılmış sadece iki tanesi kritik yoğun bakım hastalarında yapılmıştır.

Beslenme desteği alan kritik yoğun bakım hastalarında hiperglisemi gelişimi sık görülen bir durumdur.
Hipergliseminin kritik hastalarda kötü klinik sonuçlarla ilgili olduğu düşünülmektedir ve hipergliseminin kontrol altına alınmasının, hastanın diyabet öyküsü olsun ya da olmasın klinik sonuçları anlamlı olarak iyileştireceği öne sürülmektedir(4).

Van den Berghe ve ark ${ }^{(3)} 2001$ yılında cerrahi yoğun bakım hastalarında yapmış olduğu çalışma (Leuven 1), yoğun insülin tedavisinin kritik hastada mortalite ve morbidite üzerine etkisini inceleyen ilk çalışmadır. 1548 hasta çalışmaya dahil edilmiştir ve hastaların çoğu kardiyak cerrahi sonrası takip edilen hastalardır. Mekanik ventilasyon desteği alan cerrahi yoğun bakım hastaları iki gruba ayrılmış; bir gruba kan şekerini 80-110 mg/dl arasında tutacak şekilde, diğer gruba ise kan şekerini 180-200 mg/dl arasında tutacak şekilde insülin tedavisi uygulanmıştr. Sıkı kan şekeri kontrolü grubunda hem yoğun bakım mortalitesinin hem de hastane mortalitesinin azaldığı gösterilmiştir. Bu etkinin yoğun bakım ünitesinde 5 gün ve daha uzun süre kalan cerrahi hastalarında daha bariz olarak ortaya çıktığı belirtilmiştir.

Van den Berghe ve arkadaşları ${ }^{(5)} 2006$ yılında, 1200 hastanın katılığı ve dahili yoğun bakım hastalarında yapmış oldukları çalışmada (Leuven 2); yoğun insülin tedavisinin mortalite üzerine istatistiksel olarak anlamlı etkisinin saptanamadığını; ancak morbiditeyi azalttığını belirtmişlerdir. Bu çalışmada da sıkı kan şekeri aralığı 80-110 mg/dl olarak belirlenmiştir. Çalışmanın sonunda sıkı kan şekeri kontrolü yapmanın ciddi hipoglisemik atak sıklığında 6 kat artış yaptığı görülmüş ve hipoglisemi, mortalite açısından bağımsız risk faktörüdür denilmiştir. Biz çalışmamızda; hipogliseminin kritik hastalarda mortalite riskini daha fazla artırdığı düşüncesiyle sıkı kan şekeri aralığı olarak 80-150 mg/dl' yi belirledik.

VISEP ve GLUCONTROL çalışmaları 2008 yııında yapılımış çok merkezli, randomize, kontrollü çalışmalardır ancak her iki çalışmanın sonuçları, çalışmalar tamamlanmadan yayınlanmıştır. VISEP çalışması 18 merkez ve 537 hasta katıımı ile yapılmışır. Çalışmanın sonucunda 28 günlük mortalite ve organ yetmezliği skorunda konvansiyonel grup ile yoğun insülin tedavisi alan grup arasında fark olmadığı açıklanmıştır. GLUCONTROL çalışması ise toplam 21 merkez ve 1101 hasta katıımı ile yapılmış bir çalışmadır. Bu çalışmada da yine iki tedavi grubu arasında yoğun bakım mortalitesi açısından fark bulunamamıştır. Her iki çalışma da; ciddi hipoglisemi (< $40 \mathrm{mg} / \mathrm{dll})$ oranının yoğun insülin tedavisi alan grupta çok fazla olması nedeniyle erken sonlandırılmıştır (6,7).

Bütün bu tartışmaların arasında 2009 yılında NICESUGAR çalışmasının sonuçları açıklanmıştır. Dahili ve cerrahi 
hastalarının karışık olarak alındığı çalışma; 42 merkez ve 6104 hasta katıımı ile gerçekleşmiş randomize, kontrollü bir çalışmadır. Yoğun bakımda 3 gün ve daha fazla kalması beklenen hastalar ilk 24 saatte 2 gruba ayrilarak randomize edilmiş. Yoğun insülin tedavisi alan grupta kan şekeri 81-108 $\mathrm{mg} / \mathrm{dl}$; konvansiyonel tedavi grubunda ise $180 \mathrm{mg} / \mathrm{dl}$ ve altı hedeflenmiştir. 90 günlük mortalite primer sonlanım noktası olarak belirlenmiştir. Hem cerrahi hem de dahili yoğun bakım hastalarında; yoğun insülin tedavisi alan grupta 90 günlük mortalite oranlarının anlamlı olarak yüksek bulunduğu belirtilmiştir. Yine bu grupta kardiyovasküler nedenlerle ölümler daha yüksek bulunmuş, ciddi hipoglisemi atakları daha fazla görülmüştür. Sonuçta bu çalışma kritik hastada kan şekerinin $110 \mathrm{mg} / \mathrm{dl}$ altına düşürülmemesini önermektedir. Bizim çalışmamızda da NICE-SUGAR çalışmasının mortalite oranları göz önüne alınarak sıkı kan şekeri hedefi olarak 80$150 \mathrm{mg} / \mathrm{dl}$ aralığı belirlenmiştir(8).

Joseph B ve ark ${ }^{(9)}$ yayınladıkları bir çalışmada, sıkı kan şekeri kontrolünün hastanede yatan tüm hastalar için bir bakım standardı haline geldiğinden bahsetmişler ve iki yıl boyunca cerrahi servislerine yatan toplam 461 hastayı 3 alt gruba ayırarak incelemişler ve bir gruba sıkı glisemik kontrol protokolüne göre insülin tedavisi verilmiş. Çalışmada kan şekeri aralıklarını; hipoglisemi <50 mg/dl, sıkı kan şekeri 80$150 \mathrm{mg} / \mathrm{dl}$, orta düzey hiperglisemi 150-250 mg/dl, major hiperglisemi $>250 \mathrm{mg} / \mathrm{dl}$ olarak belirlemişler. Çalışmanın sonunda standart bir sıkı kan şekeri kontrolü protokolünün uygulanmasının zor olsa da; güvenle tatbik edilebileceği belirtilmiş ve hipoglisemik ataklarda artış olmadığı ifade edilmiştir.

Patel GW ve ark ${ }^{(10)} 2009$ yılında yapmış oldukları retrospektif bir çalışmada, hastanede yatış sırasında hiperglisemi gelişiminin, diyabet tanısı olan veya olmayan hastalarda endişe verici olduğu belirtilmiş ve 2007-2008 yılları arasında hastanede yatan hastaları 2 gruba ayırarak geleneksel insülin tedavisi uygulama algoritması ile sıkı glisemik kontrol algoritması uygulanan hastaları karşılaştırmışlardır. Çalışmanın birincil sonlanım noktasının 80-150 mg/dl hedef aralığındaki toplam kan şekeri ölçümlerinin yüzdesi olarak belirlemişlerdir. Yine bu çalışmada da sıkı glisemik kontrol aralığının 80$150 \mathrm{mg} / \mathrm{dl}$ olarak seçilme nedeninin yüksek hipoglisemi oranlarından kaçınmak olduğu belirtilmiştir. Çalışmanın sonunda iki grup arasında hipoglisemi saptananlarının sıkı glisemik kontrol grubunda daha fazla olduğu ancak herhangi bir klinik sekel olmadığı ifade edilmiştir.

Peters A ve ark ${ }^{(11)}$ yapmış olduğu tip 1 diyabet tanılı hastalar üzerindeki çalışmada diyabetik enteral ürün ile standart enteral ürünün glisemik kontrol üzerine etkilerini incelemişlerdir. Çalışmanın sonunda standart ürün ile beslenen hastalarda kan glukoz düzeyleri sürekli bir artış gösterirken diyabetik ürün ile beslenen hastalarda kan glukoz düzeylerinin kararlı düzeyini koruduğu gösterilmiştir. Bizim çalışma hastalarımız diyabet tanısı konulmamış kritik hastalardan seçilmişlerdir.

Grahm ve ark ${ }^{(12)}$, yaptığı bir çalışmada, glucerna ile vital HN (yüksek karbonhidratlı semi-elemental beslenme ürünü) ürünlerini, akut kafa travmalı steroid tedavisi almayan hastalar üzerinde karşılaştırarak incelemişlerdir. Çalışmanın hedefi, stresin oluşturduğu glukoz intoleransı koşulları altında ölçülen kan glukoz düzeyleri üzerine her iki beslenme ürününün etkilerini karşılaştırmaktır. Diyabetik ürün ile beslenen hastaların günlük kan glukoz düzeyleri bazal değerden ve yüksek karbonhidratlı ürün ile beslenen hastaların kan glukoz düzeylerinden anlamlı olarak daha düşük bulunmuştur. Ayrıca diyabetik ürün ile beslenen grupta insülin ihtiyacı olmazken, diğer gruptaki hastalara insülin verilmesi gerekmiştir.

Elia M ve ark ${ }^{(13)}$, yayınladıkları meta-analizde, oral destek ürünleri (16 çalışma) ve nazogastrik tüp yoluyla beslenen (7 çalışma) hastaları içeren çalışmaları dahil etmiş ve diyabetik beslenme ürünü ile standart beslenme ürününü karşılaştırarak incelemiştir. Araştırma diyabetik üründe, tokluk kan glukoz düzeyleri ve zirve glukoz düzeylerinin standart ürüne göre anlamlı derecede düşük olduğunu göstermiştir. 3 adet randomize kontrollü çalışmada ve 1 adet klinik kontrollü çalışmada diyabetik ürün ile beslenen hastaların insülin intiyacının standart ürün ile beslenenlere göre azaldığı rapor edilmiştir. Bu durum diyabetik hastalarda hastalık spesifik beslenme ürünü kullanmanın standart ürüne göre glisemik kontrolü daha kolay sağlayabileceğini göstermektedir. Diyabetik ürünün içeriğinde bulunan (yüksek tekli doymamış yağ asidi, düşük karbonhidrat ve lif) besin öğelerinin mide boşalımını (yağ ve lif), karbonhidratın intestinal emilimini (lif) geciktirerek ve daha düşük oranda glisemik yanıta yol açarak (fruktoz) glisemik kontrolü kolaylaştırdığı sonucuna ulaşılmıştır.

Yokoyama ve ark(14), yaptığı randomize, cross-over çalışmada sağlıklı gönüllüler ve tip 2 diyabetik hastalarda diyabetik ürün (yüksek tekli doymamış yağ asidi içeren enteral beslenme ürünü) ile standart ürün (yüksek karbonhidratlı enteral beslenme ürünü) karşılaştırılmış ve plazma glukoz konsantrasyonu, insülin sekresyonu üzerine olan etkilerini incelemişlerdir. Çalışmanın sonucunda araştırmacılar diyabetik 
ürünün standart ürüne göre aşııı insülin sekresyonuna neden olmadan postprandiyal hiperglisemiyi baskıladığını öne sürmüşlerdir.

Greet Van den Berghe ve ark ${ }^{(15)}$, yapmış oldukları bir derlemede yoğun bakımlarda şeker kontrolü üzerine yapılan çalışmaları değerlendirmişler ve sıkı kan şekeri kontrolünün doğru bir izlem ve güvenilir bir insülin protokolü sağlandığında erken parenteral beslenme alan hastalarda güvenli ve etkili olduğunu bulmuşlardır. Her ne kadar kritik hastalar için optimal kan şekeri belirsiz olsa da; bu hasta grubunda şiddetli hiperglisemi ve hipoglisemi atakları ile kan şekeri değerlerindeki büyük değişimleri önlemenin daha intiyatlı ve güvenilir olacağını belirtmişlerdir.

Bizim çalışmamızda farklı sonuçların elde edilmesini, hasta popülasyonunun farklı olmasına ve vaka sayısının azlığına bağlayabiliriz. Bu konuda vaka sayısının daha fazla olduğu çalışmalara intiyaç olduğunu söyleyebiliriz 


\section{Kaynaklar}

1. Moral AR, Demirağ K. Yoğun bakımda beslenme. In: Tüzüner F, editör. Anestezi yoğun bakım ağrı. 1. Baskı. Ankara: MN Medikal \& Nobel; 2010. s. 1487-95.

2. Mesejo A, Acosta JA, Ortega C, Vila $\mathrm{J}$, Fernandez $\mathrm{M}$, Ferreres $\mathrm{J}$ ve ark. Comparison of a high- protein diseasespesific enteral formula with a highprotein enteral formula in hyperglycemic critically ill patients. Clinical Nutrition 2003; 22(3):295-305

3. Van den Berghe $G$, Wouters $P$, Weekers F, Verwaest C, Bruyninckx F, Schetz $M$ ve ark. Intensive insulin therapy in critically ill patients. N Engl J Med 2001; 345:1359-67.

4. McMahon MM, Miles JM. Glycemic control and nutrition in the intensive care unit. Current Opinion in Clinical Nutrition and Metabolic Care 2006; 9:120-3.

5. Van den Berghe G, Wilmer A, Hermans G, Meersseman W, Wouters PJ, Milants I ve ark. Intensive insulin therapy in the medical ICU. N Engl J Med 2006; 354: 449-461.

6. VISEP: Brunkhorst FM, Engel C, Bloos F, Meier-Hellmann A, Ragaller M, Weiler $\mathrm{N}$ ve ark. German Competence Network
Sepsis (SepNet): Intensive insulin therapy and pentastarch resuscitation in severe sepsis. N Engl J Med 2008; 358: 125-39.

7. Preiser JC, Devos P, Ruiz-Santana S, Me'lot C, Annane D, Groeneveld J ve ark. A prospective randomised multicentre controlled trial on tight glucose control by intensive insulin therapy in adult intensive care units: The Glucontrol study. Intensive Care Med 2009; 35: $1738-48$.

8. NICE-SUGAR: Finfer S, Chittock DR, Su SY, Blair D, Foster D, Dhingra $V$ ve ark. Intensive versus conventional glucose control in critically ill patients. N Engl J Med 2009, 360: 1346-1349.

9. Joseph B, Genaw J, Carlin A, Jordan J, Talley J, Rubinfeld I. Perioperative tight glycemic control: The challenge of bariatric surgery patients and the fear of hypoglycemic events. The Permanente Journal Spring 2007; $11: 2$.

10. Patel GW, Roderman N, Lee KA, Charles MM, Nguyen D, Beougher $P$ ve ark. Sliding scale versus tight glycemic control in the noncritically ill at a community hospital. Ann Pharmacother 2009; 43:1774-80.
11. Peters A, Davidson $M$, Isaac R M. Lack of glucose elevation after simulated tube feeding with a low-carbohydrate, highfat enteral formula in patients with type I diabetes. Am J Med 1989; 87:178-82.

12. Grahm TW, Zadrozny DB, Harrington T. The benefits of early jejunal hyperalimentation in the head-injured patient. Neurosurgery 1989;25(5):729735.

13. Elia N, Ceriello A, Laube H, Sinclair AJ, Engfer M, Stratton RJ. Enteral nutritional support and use of diabetes-spesific formulas for patients with diabetes: a systematic review and meta-analysis. Diabetes Care 2005; 28:2267-79.

14. Yokoyama J, Someya Y, Yoshihara, Ishii $\mathrm{H}$. Effects of high-monounsaturated fatty acid enteral formula versus high-carbohydrate enteral formula on plasma glucose concentration and insulin secretion in healthy individuals and diabetic patients. The Journal of International Medical Research 2008; 36:137-46

15. Gunst J, De Bruyn A, Van den Berghe G. Glucose control in the ICU. Curr Opin Anesthesiol 2019; 32:000-000. 